Article

\title{
System Dynamics Model for the Evolutionary Behaviour of Government Enterprises and Consumers in China's New Energy Vehicle Market
}

\author{
Hongxia Sun *, Yao Wan * (D) and Huirong Lv \\ Business School, Beijing Technology and Business University, Beijing 100048, China; lvhuirong26@126.com \\ * Correspondence: sunhongxia@btbu.edu.cn (H.S.); wanyao2017@163.com (Y.W.)
}

Received: 16 December 2019; Accepted: 16 February 2020; Published: 20 February 2020

\begin{abstract}
Exhaust pollution and energy crises are worsening worldwide. China has become the largest motor vehicle producer; thus, promoting the use of new energy vehicles (NEVs) in China has important practical significance. In this paper, considering the limited rationality of governments, NEV enterprises and consumers, we study the subsidy policy of the China NEV market using the evolutionary game and system dynamics (SD) methods. First, a tripartite evolutionary game model is developed and the replicator dynamics equations and Jacobian matrix are obtained. A SD simulation of the model was conducted to further clarify the impact of the initial market proportion and three variables used in the model. The results show that the initial market proportion affects the evolution speed but does not affect the evolution result when the three group players all choose a mixed strategy. For governments, they should not hastily cancel price subsidies provided to consumers; rather, they should dynamically adjust the rate of the subsidy decrease and increase the consumers' extra cost for purchasing fuel vehicles (FVs). NEV enterprises should appropriately increase their investments in the research and development $(R \& D)$ of NEVs.
\end{abstract}

Keywords: new energy vehicle; R\&D investment; government subsidy; system dynamics

\section{Introduction}

Vehicles provide considerable convenience to consumers, although they also cause air pollution. Exhaust pollution and energy crises are becoming worse in the 21st century [1], and new energy vehicles (NEVs) are important for addressing these pollution issues [1,2]. However, the sales of NEVs account for only a small portion of the current automotive market [3]. For example, in 2018, the sales volume of NEVs in China was 1.27 million, accounting for only $4.47 \%$ of the national automobile sales. In 2019, the World NEV Conference proposed that the global market share of NEVs should reach $50 \%$ by 2035 , and the global automotive industry should basically realise the transformation to automobile electrification. The Ministry of Ecology and Environment of the People's Republic of China released 2018 annual reports regarding vehicle environmental management and noted that China has been the largest motor vehicle production and marketing country in the world for nine consecutive years. Thus, motor vehicle pollution has become an important source of air pollution in China and represents an important cause of haze and photochemical pollution. Therefore, under the premise that the development of NEVs still faces many problems, such as immature technology, a relatively high cost and imperfect environment, it is necessary to study the development of NEVs to help the Chinese government and automobile enterprises understand how to make strategic choices, which can effectively drive consumers to choose NEVs.

For the government, effective policies must be developed to stimulate the market. In the process of urbanisation in China, environmental governance faces enormous challenges. The government needs 
to coordinate the interests of various entities and promote energy conservation and emission reduction via the improvement of the system [4], establishment of a green economy, and realisation of sustainable growth $[5,6]$. To induce the development of the electric vehicle (EV) industry in its early stage, many countries have taken action to develop economic plans and provide incentives for NEV enterprises and consumers to encourage the implementation of NEVs; among these incentives, taxes and subsidies are the most common [1]. France and South Korea mainly promote NEVs according to subsidising vehicle prices. The incentives policy of the French government for NEV market is strengthening the subsidies and improving public facilities. The French government began to implement the subsidy policy in 2008; the subsidy was increased twice in 2014 and 2016; and the purchase cost of consumers decreased step by step. In 2015, France increased the construction of public charging facilities and built 8165 public charging piles, which greatly improved the convenience of consumers to use NEVs. At the end of 2015, South Korea announced the plan of future environment-friendly models, and plans to keep more than 1 million NEVs in 2020 to reduce greenhouse gas emissions. Each hydrogen fuel cell vehicle can receive a subsidy of 27.5 million won, while the subsidies for pure electric vehicles and hybrid vehicles are reduced to 12 million won and 1 million won, respectively. Norway and the United States mainly use the tax relief policy to subsidise consumers who purchase NEVs. According to the European Automobile Industry Association, in 2013, Norway was the country with the most promotion and the most preferential policies among European countries. In Norway, the purchase of NEVs is exempt from registration tax and $25 \%$ value-added tax, and it also has a toll-free policy. In 2008, the United States passed the Energy Improvement and Extension Act. According to the act, eligible taxpayer can enjoy the corresponding tax return for the new qualified plug-in hybrid vehicles and pure electric vehicles purchased after December 31, 2009. In China, government taxes and subsidies policy are implemented together. In December 2017, the Ministry of Finance of the People's Republic of China announced that, from 1 January, 2018 to December 31, 2020, NEVs will be exempt from the vehicle purchase tax. In addition to subsidies and preferential policies for consumers to purchase $\mathrm{NEV}$, the government has also invested a lot of funds to encourage enterprises to carry out R\&D and innovation. In September 2012, the Ministry of Finance and the Ministry of Industry and Information Technology jointly issued the notice on organising and carrying out the technological innovation project of the NEV industry (http://www.nea.gov.cn/2012-10/16/c_131908404.htm). The central government arranged a special fund of 4 billion yuan to encourage NEV enterprises to improve their technological innovation capabilities. The government's incentive measures have effectively stimulated the NEV market. Sales of NEVs increased significantly in 2018. For example, according to data obtained from the China Passenger Car Association, the sales volume of domestic new energy passenger vehicles in 2018 was 9.93 billion, which represented an increase of $90.4 \%$ over the previous year. However, China's NEV market is still a policy-driven market due to the loose subsidy policies that were established in the past. Recently, new subsidy policies have been introduced. In June 2019, the Beijing Finance Bureau, Beijing Municipal Transportation Commission and other units jointly issued a notice regarding the adjustment of the relevant aspects of Beijing's NEV management measures and the cancellation of municipal financial subsidies for battery EVs. The cancellation of Beijing's municipal subsidies for battery EVs implies a downward trend in subsidy policies, and future subsidy policies may be completely cancelled. However, government subsidies have a significantly positive impact on R\&D of enterprises [7]. Therefore, to stimulate the development of NEV market, the government may choose to strengthen the R\&D subsidy policy for enterprises. In general, the current subsidy policy may still lead to improvements [8]. It is significant to explore the government policy choose behaviour. The reactions of the major participating groups in the NEV market have become an important reference for future policy formulation.

NEV enterprises should not rely excessively on government decision-making and instead should focus on improving core competitiveness and investing in the research and development (R\&D) of NEVs. Since 2008, to promote the rapid development of the NEV industry, the Chinese government has been leading the world in high-volume subsidies and preferential tax relief. However, the price subsidy 
policy for NEV consumers has gradually reached an end, and the notification for subsidy reductions has been finalised. The government encourages enterprises to invest in R\&D with corresponding policies. The development of most NEV enterprises is still in its infancy. The prominent problem restricting the development of NEV industry is the lack of core technology [9]. Therefore, for enterprises, in the process of producing NEVs, it is very important to decide whether to choose high or low R\&D investment. The uses of policies alone cannot maintain the healthy and sustainable development of the NEV industry, and only fair market competition can promote the continuous development of the NEV industry.

For consumers, changes in government policies, as well as different $R \& D$ levels and pricing strategies used by NEV enterprises, will directly affect whether consumers will choose NEVs or fuel vehicles (FVs). Due to the improvement in China's economy and the populations' purchasing power, China has become one of the largest consumer markets in the world [10]. Therefore, it is necessary to study the behavioural strategies that Chinese consumers use when purchasing NEVs and FVs.

In this paper, we use evolutionary game theory combined with system dynamics (SD) to systematically study government policy choices, NEV enterprise strategy choices and consumer purchase choices in the increasingly complex competitive market. We consider that the governments, NEV enterprises and consumers exhibit bounded rationality; they continuously learn from multiple games and seek the evolutionary stable strategy (ESS) to achieve the optimal equilibrium. The main objectives of this paper are (1) to study the behavioural strategies of governments, NEV enterprises and consumers under different initial market proportions and factors through a simulation analysis; and (2) to explore how government policies and NEV enterprises' R\&D investments can effectively guide a larger proportion of consumers to choose NEVs.

The remainder of this paper is organised as follows. Section 2 reviews the related literature. Section 3 establishes an evolutionary game model and constructs replicator dynamics equations. Section 4 presents a tripartite evolutionary game simulation analysis based on SD. Finally, Section 5 provides the conclusions and directions for further research.

\section{Literature Review}

\subsection{Government Subsidy Policy for the NEV Market}

There are different types of NEV, such as electric vehicle, hybrid electric vehicle, plug-in hybrid electric vehicle, etc. To study the NEV market, many researchers have focused on subsidy policies for the NEV markets in different countries and have conducted empirical analyses. Driscoll et al. [11] conducted an empirical study on the EV market in Ireland and showed that only larger financial subsidies could achieve the market growth target set by the government in the short term. Hirte and Tscharaktschiew [12] conducted an empirical analysis of the German EV market and showed that, in a spatial urban environment, the optimal tax rate depends on the interaction effect of transport-related externalities in taxation and the redistribution effect through the operation of the urban land market and deduced that, in large German cities, EVs should be taxed rather than subsidised. Li et al. [13] used firm-level data from the Zhongguancun Science Park to explore the determinants of the development of the NEV industry in China and showed that government subsidies are beneficial for increasing the efficiency of large NEV firms. Yang and Tang [14] established a random coefficient discrete choice model to study the effectiveness and welfare consequences of various subsidy programs of government in Chinese NEV market.

Scholars have also conducted theoretical analyses. Wu et al. [15] constructed a two-period imperfect information game theory model to study charging pile construction in the Chinese automobile market and showed that the lack of charging piles hinders the development of China's NEV market and China still needs to subsidise the construction of charging piles. Li et al. [16] used non-cooperative game models to analyse the impacts of subsidy policy and dual credit policy on NEV market. Luo et al. [17] investigated an automobile supply chain made up of manufacturers and retailers, indicating that 
a favourable discount rate and subsidy ceiling can improve the development of the EV market. Sun et al. [18] constructed an agent-based simulation model and using data on the U.S. automobile market in 2010 found that a government subsidy is more effective for consumers than manufacturers. Yang et al. [19] used a Cournot duopoly model to analyse government support policies including subsidies and found that tariffs can effectively expand the market share of domestic NEVs when less technology is available. Zuo et al. [20] employed three-way decision theory to identify an effective decision-making mechanism for government R\&D subsidies.

The above studies assessed government subsidies for NEV markets through either empirical analyses or theoretical analyses, and most of the literature focused on higher government subsidies that can improve the development level of the NEV market but ignored the important role that consumers play in the NEV market and the fact that government policy constantly changes. In this paper, we consider the most recent policies regarding China's NEV market and the bounded rationality of the governments, NEV enterprises and consumers to explore the effect of the different strategies used by the three members.

\subsection{Application of Evolutionary Games to NEV Markets}

Evolutionary game theory is based on Darwin's theory of biological evolution and Lamarck's theory of genetics [21] and claims that the game players are subject to bounded rationality. This study takes the group of game players as the research object. The replication dynamic equation and evolutionary stability strategy are two important concepts in evolutionary game theory. The replication equation describes the growth rate of a strategy's use in a population, that is, the difference between the adaptive value and the average adaptive value when the strategy is selected. A replication dynamic equation is a dynamic differential equation. When a group elects to use a strategy to achieve higher returns than the average returns of the group, the strategy of this group can be emulated by the whole group, since replication dynamics not only effectively depict the mutual transformation and dynamic adjustment of the game population and its behaviour but also reflect the field stability of the stable behaviour of the population. Thus, replication equations [22] are selected to analyse the model, and the game equilibrium of the group's strategy can be obtained.

Researchers studied NEV market problems using an evolutionary game model involving auto manufacturers and governments. Wang et al. [23] used static game theory and evolutionary game theory to explore the different strategies and actions of NEV manufacturers under different governmental punitive and incentive policy scenarios considering consumer environmental awareness. Liu et al. [1] established an evolutionary model to study the impact of government emission taxes and subsidies on vehicle manufacturers' decisions and the dynamic trends of the EV industry. Other researchers have established evolutionary game models involving auto manufacturers and consumers. Li et al. [13] studied the dynamic influence of government policy on EV diffusion in different networks using a complex network evolutionary game method.

However, most of the literature used evolutionary game theory to study NEV markets and considered only the game between the government and the automobile manufacturers or between the automobile manufacturers and the consumers, ignoring the fact that the strategies of the three players affect each other. Therefore, when researching the interactions among the government, automobile manufacturers and consumers, it is most reasonable to choose the tripartite game.

\subsection{Application of $S D$}

The SD concept was proposed by Jay W. Forrester of the MIT Sloan School of Management in 1950 [24]. SD is a combination of system theory, cybernetics, servo mechanism, information theory, decision theory and computer simulation, and it is a process-oriented research method that is suitable for studying many variables and non-linear systems. The causal feedback mechanism is transmitted layer by layer in the whole SD model, which can be applied to various research issues such as the global environment and energy consumption. SD models are able to effectively address numerous 
aspects, such as the economy, energy, society, and management. Scholars have studied and discussed many scientific research problems by constructing composite SD models.

Trappey et al. [25] established a green transportation policy evaluation model for Penghu Island using a SD approach and simulated the behaviour of a green transportation system and related policy effects in a small, controlled environment. Lee et al. [26] combined SD with consumer choice models, proposed a new hybrid EV market penetration model, empirically analysed the Korean hybrid vehicle market penetration rate and estimated the future effects of different policies on bottlenecks. Zhang et al. [27] proposed a pricing model for the charging of EVs in Beijing based on SD. Lu et al. [28] proposed a SD model to simulate different levels of financial subsidies, the distribution of the financial subsidies and the demand for civilian vehicle ownership in China's EV industry through 2020. Sun and Wang [29] proposed a SD model based on a competitive Lotka-Volterra model to study and predict the market evolution of NEVs and traditional fuel vehicles (TFVs) in China because of the competition and substitution phenomenon between TFVs and NEVs.

The abovementioned research has shown that, regardless of whether NEVs, emerging technology industries or the renewable energy field are considered, government subsidies have positive strategic significance for rapid development. The main research methods used in the abovementioned literature focused on investigation and research, empirical data analysis and game theory. However, in some regions, government subsidies will reduce social welfare. For example, in Germany and Ireland, although subsidies promote the development of local NEVs, they reduce the overall social welfare [12].

Many scholars believe that evolutionary game models are suitable for exploring the influencing mechanisms that exist among the government, enterprises and consumers. Furthermore, evolutionary game models are helpful for performing quantitative analyses of some policy formulation criteria. When studying NEV market problems, evolutionary game models are used to quantitatively optimise the strategic choices of either the government and automobile manufacturers or the automobile manufacturers and consumers.

Many scholars use SD to study the feedback mechanisms of many complex social and economic problems. SD models can be used to explore the interactions between various factors in complex networks. By combining game theory with other mathematical functions, many social problems can be quantitatively analysed to scientifically optimise policy making or strategic choices. Accordingly, this paper mainly studies the following:

(1) China's NEV market is constantly changing and previous study conclusions do not apply to the current Chinese NEV market environment. Moreover, several policy variables have already changed. This paper focuses on policy optimisation and upgrading that occurred after 2015.

(2) Future market competition will be based on science and technology. This paper focuses on the role of R\&D investment in the whole system. As China's economic and social development has reached a certain level, the significant impact of consumer awareness on the entire NEV market cannot be ignored.

(3) Few studies on the development of China's NEV market have proposed targeted policy recommendations for the NEV market beyond 2020 and conducted corresponding quantitative analyses.

\section{Evolutionary Game Model Formulation and Discussion}

\subsection{Model Assumptions and Formulation}

The notations used to develop the proposed models are provided in Table 1. 
Table 1. Notations.

\begin{tabular}{ll}
\hline Symbol & Description \\
\hline Government parameters & Government price subsidies for consumers purchasing NEVs \\
$S_{1}$ & Government R\&D subsidies for enterprises \\
$S_{2}$ & Regulatory cost of government price subsidy policy \\
$C_{1}$ & Regulatory cost of government R\&D subsidy policy \\
$C_{2}$ & Input cost of controlling exhaust pollution \\
$C_{3}$ & Coefficient of an enterprise's contribution to the government by selling an \\
$\alpha$ & NEV \\
$k$ & Coefficient of revenue contributes to the government when an FV is sold \\
$R_{3}$ & Additional benefits of consumers' contributions to the government by \\
Enterprise parameters & purchasing NEVs \\
$M_{1}$ & R\&D Cost of each NEV with high R\&D investment \\
$P_{1}$ & Price of each NEV with high R\&D investment \\
$M_{2}$ & R\&D Cost of each NEV with low R\&D investment \\
$P_{2}$ & Price of each NEV with low R\&D investment \\
$\delta$ & Risk probability of low R\&D investment unable to obtain the subsidy \\
Consumer parameters & \\
$F_{1}$ & Benefit of each high R\&D investment NEV for consumers \\
$F_{2}$ & Benefit of each low R\&D investment NEV for consumers \\
$F_{3}$ & Benefit of each FV for consumers \\
$E$ & Purchase tax payable on each FV \\
$P_{3}$ & Price of each FV \\
$P_{4}$ & Consumers' extra cost for purchasing FVs. \\
$Q_{1}$ arket parameters & Monthly sales of NEVs \\
$Q_{2}$ & Monthly sales of FVs \\
\hline
\end{tabular}

To analyse the conflict of interests and optimal strategies of the government, NEV enterprises (we use enterprises for simplicity) and consumers, several assumptions are made as follows:

(1) Governments have two strategies: they either choose the price subsidy policy or choose the R\&D subsidy policy. Government subsidies can be divided into industrial subsidies and consumption subsidies in China [7]. To support the healthy development of the NEV market and reduce pollution from vehicle exhaust, the government subsidises enterprises and consumers who purchase NEVs through R\&D subsidies for enterprises and price subsidies for consumers. A price subsidy is a direct deduction for consumers, and it is exempt from vehicle purchase tax. Enterprises can receive the same purchase subsidy by using sales catalogues. Recently, there has been a downward trend in subsidy policies, which may be completely cancelled in 2020. The R\&D subsidy is a one-time disbursement for $R \& D$ activities given by the government to enterprises who choose high $R \& D$ investment. The $R \& D$ subsidy mainly encourages enterprises to develop safe, stable and long-lasting NEVs to effectively guide the NEV market from the subsidy market to the competition market.

(2) According to the current implementation of subsidy policies in China's NEV market, if governments choose the price subsidy policy, they may increase the subsidy standard for NEVs in the future and enterprises with lower R\&D levels may face the possibility of not receiving price subsidies. If governments choose to implement the R\&D subsidy policy, then the R\&D situation of enterprises will be affected; thus, they must decide whether to grant $R \& D$ subsidies to enterprises based on their actual R\&D levels. Governments verify the implementation of the two subsidies. Because governments have been affected by incidents regarding the misuse of subsidies, they have strengthened the supervision of enterprises and thus pay supervision costs $C_{1}$ and $C_{2}$ for the price subsidy and R\&D subsidy policies, respectively. The misuse of subsidies can be detected and severely punished; thus, in this model, governments assume that enterprises will correctly receive subsidies according to the regulatory system. 
(3) The government's R\&D subsidies for enterprise $S_{2}$ are annual subsidies. According to the current national policy, $S_{1}$ is set to decline year by year, $S_{2}$ is expected to show an upward trend in the future, and $S_{2}>S_{1}$. The parameter setting in this paper is mainly based on the development guide for the charging infrastructure of EVs (2015-2020), the announcement of the financial support policy for the promotion and application of NEVs from 2016 to 2020, the notice on the incentive policies for the charging infrastructure of NEVs during the 13th five-year plan period and the promotion and application of NEVs, the announcement of an adjustment of the financial subsidy policy for the promotion and application of NEVs and other government policy documents.

(4) Enterprises can choose from two strategies: high R\&D investment or low R\&D investment. The sales price of each NEV with high R\&D investment $P_{1}$ is greater than that with low R\&D investment $P_{2}$; that is, $P_{1}>P_{2}$. Let $P_{3}$ denote the sales price of each FV. Considering that the annual price change of same type vehicles is not obvious, we set the price as a constant value. For example, the Honda CR-V is one of the top five best-selling vehicles in the world in 2019; the 2008 Honda CR-V sold for 189.8 thousand yuan, while the 2020 Honda CR-V sold for 169.8 thousand yuan, with little change in price. NEVs are priced similarly: the Model $S$ is a high-end electric vehicle produced by Tesla; while the 2014 Model S 85 sold for 734.0 thousand yuan, the 2019 Model S long range sold for 722.8 thousand yuan. Due to uneven product quality in the current NEV market, some enterprises produce low-quality NEVs with a short range. These NEVs are mostly produced for the purpose of obtaining subsidies. In the future, governments may exclude these enterprises from the subsidy list. When enterprises choose low R\&D investment, they are faced with risk $\delta(0<\delta<1)$ that the sold NEVs do not qualify for the government's price subsidies, and this risk increases over time. High R\&D investment in NEVs will attract consumers to purchase NEVs.

(5) Consumers can choose between two strategies: purchase an NEV or purchase an FV. When consumers purchase an NEV, the governments will grant some price subsidies and tax exemptions [1]. The new high-endurance NEVs developed and produced by enterprises will cause the consumers to prefer the NEVs over the FVs. Consumers' high expectations for NEVs will force NEV enterprises to strengthen their investment and R\&D efforts to achieve breakthroughs and improvements in key technologies (http://www.sohu.com/a/224719311_151284). The benefits of FVs for consumers will decrease over time, and the consumers' extra cost for purchasing FVs $\left(P_{4}\right)$ will increase over time because the government prevents an increase in the consumers that purchase FVs. The Beijing Municipal Commission of Transport issued a notice on the total number and allocation ratio of passenger cars in 2018 and stated that the total number of passenger cars in 2018 will be reduced from 150,000 to 100,000 , with 60,000 new energy targets unchanged and 40,000 ordinary ones reduced from 90,000 , which implies the validity of our above assumption. Specifically, considering the future trend of automobile consumption, when governments choose to implement subsidy policies (including price subsidies and R\&D subsidy policies) and enterprises choose high R\&D investments, it is assumed that the benefit to consumers by choosing to purchase FVs is 0 .

(6) Let $\alpha(0 \leq \alpha \leq 1)$ and $k(0 \leq k \leq 1)$ denote the coefficient of an enterprise's contribution to the government by selling an NEV or an FV, respectively; then, the annual benefits that NEV markets contribute to the government by selling NEVs are $\alpha P_{i} Q_{1}(i=1,2)$ and the annual benefits that FV markets contribute to the governments by selling FVs are $k P_{3} Q_{2}$. The benefits that consumers provide to government $\left(R_{3}\right)$ are reflected in a reduction of both emissions and oil consumption. Conversely, consumers who choose to purchase FVs will increase the governments' cost associated with air pollution $C_{3}$.

(7) Let $x(0 \leq x \leq 1)$ denote the proportion of governments that choose to implement price subsidy policies, and let $1-x$ denote the proportion of governments that choose to implement R\&D subsidy policies. Suppose that $y(0 \leq y \leq 1)$ represents the proportion of enterprises who choose high $R \& D$ investment and $1-y$ represents the proportion of enterprises who choose low R\&D investment. Additionally, let $z(0 \leq z \leq 1)$ denote the proportion of consumers who choose to purchase NEVs and $1-z$ denote the proportion of consumers who choose to purchase FVs. 
Based on these assumptions, the payoff matrix of the governments, enterprises and consumers is shown in Table 2. For simplicity, in Table 2, PS and RS represent the "price subsidy policy" and "R\&D subsidy policy" strategies, respectively; HI and LI represent the "high R\&D investment" and "low R\&D investment" strategies, respectively; and PN and PF represent the "purchase an NEV" and "purchase an FV" strategies, respectively. For example, when government choose PS, enterprise choose $\mathrm{HI}$ and consumer choose $\mathrm{PN}$, the payoff of the government is $\alpha P_{1} Q_{1}+R_{3}-C_{1}-S_{1} Q_{1}$, where $\alpha P_{1} Q_{1}$ represents the contribution of NEV markets to the government, $R_{3}$ represents the contribution of consumers to the government by purchasing NEVs, $C_{1}$ represents the regulatory cost of the government price subsidy policy and $S_{1} Q_{1}$ represents the government price subsidies to consumers; the payoff of the enterprise is $\left(P_{1}-M_{1}\right) Q_{1}$, i.e., the profit by selling NEVs; and the payoff of the consumer is $\left(-P_{1}+S_{1}+F_{1}\right) Q_{1}$, where $-P_{1} Q_{1}$ represents the purchase cost of NEVs, $S_{1} Q_{1}$ represents the price subsidies received from the government and $F_{1} Q_{1}$ represents the benefit of high R\&D investment NEV for consumers. When government choose RS, enterprise choose LI and consumer choose PF, the payoff of the government is $E Q_{2}+k P_{3} Q_{2}-C_{3}-C_{2}$, where $E Q_{2}$ represents tax from purchasing FVs by consumers, $k P_{3} Q_{2}$ represents the contribution of FV markets to the governments by selling FVs, $C_{3}$ represents the cost of controlling exhaust pollution and $C_{2}$ represents regulatory cost of government R\&D subsidy policy; the payoff of the enterprise is $-M_{2} Q_{1}$, i.e., the cost of NEVs with low R\&D investment by the enterprise; and the payoff of the consumer is $\left(-P_{3}-E-P_{4}+F_{3}\right) Q_{2}$, where $P_{3} Q_{2}$ represents the purchase cost of FVs, $E Q_{2}$ represents the purchased tax on FVs, $P_{4} Q_{2}$ represents the extra cost of consumers for purchasing FVs and $F_{3} Q_{2}$ represents the benefit of FV for consumers. Similarly, we can obtain the other six strategic combinations. The full range of strategic combinations is expressed as follows.

$$
\begin{gathered}
\left(\Pi_{G 1}, \Pi_{E 1}, \Pi_{C 1}\right)=\left(\alpha P_{1} Q_{1}+R_{3}-C_{1}-S_{1} Q_{1},\left(P_{1}-M_{1}\right) Q_{1},\left(-P_{1}+S_{1}+F_{1}\right) Q_{1}\right) \\
\left(\Pi_{G 2}, \Pi_{E 2}, \Pi_{C 2}\right)=\left(\alpha P_{1} Q_{1}+R_{3}-C_{2}-S_{2},\left(P_{1}-M_{1}\right) Q_{1}+S_{2},\left(-P_{1}+F_{1}\right) Q_{1}\right) \\
\left(\Pi_{G 3}, \Pi_{E 3}, \Pi_{C 3}\right)=\left(E Q_{2}+k P_{3} Q_{2}-C_{3},-M_{1} Q_{1}, 0\right) \\
\left(\Pi_{G 5}, \Pi_{E 5}, \Pi_{C 5}\right)=\left(\alpha P_{2}, \Pi_{C 4}\right)=\left(E Q_{2}+k P_{3} Q_{2}-C_{3}-C_{2}-S_{2},-C_{1}-(1-\delta) S_{1} Q_{1},\left(P_{2}-M_{2}, 0\right)\right. \\
\left(\Pi_{G 6}, \Pi_{E 6}, \Pi_{C 6}\right)=\left(\alpha P_{2}\right) Q_{1},\left(-P_{2}+S_{3}-C_{2},\left(P_{2}-M_{2}\right) Q_{1},\left(-P_{2}+F_{2}\right) Q_{1}\right) \\
\left(\Pi_{G 7}, \Pi_{E 7}, \Pi_{C 7}\right)=\left(E Q_{2}+k P_{3} Q_{2}-C_{3},-M_{2} Q_{1},\left(-P_{3}-E-P_{4}+F_{3}\right) Q_{2}\right) \\
\left(\Pi_{G 8}, \Pi_{E 8}, \Pi_{C 8}\right)=\left(E Q_{2}+k P_{3} Q_{2}-C_{3}-C_{2},-M_{2} Q_{1},\left(-P_{3}-E-P_{4}+F_{3}\right) Q_{2}\right)
\end{gathered}
$$

Table 2. Payoff matrix of a government, an enterprise and a consumer.

\begin{tabular}{cllll}
\hline \multirow{2}{*}{ Strategies } & \multicolumn{2}{l}{ Enterprise Choose HI $(\mathbf{y}=\mathbf{1})$} & \multicolumn{2}{l}{ Enterprise Choose LI $(\mathbf{y}=\mathbf{0})$} \\
\cline { 2 - 5 } & $\begin{array}{l}\text { Consumer Choose } \\
\mathbf{P N}(z=\mathbf{1})\end{array}$ & $\begin{array}{l}\text { Consumer Choose } \\
\mathbf{P F}(z=\mathbf{0})\end{array}$ & $\begin{array}{l}\text { Consumer Choose } \\
\mathbf{P N}(z=\mathbf{1})\end{array}$ & $\begin{array}{l}\text { Consumer Choose } \\
\mathbf{P F}(z=\mathbf{0})\end{array}$ \\
\hline $\begin{array}{c}\text { Government } \\
\text { choose PS } \\
(x=1)\end{array}$ & $\left(\Pi_{G 1}, \Pi_{E 1}, \Pi_{C 1}\right)$ & $\left(\Pi_{G 3}, \Pi_{E 3}, \Pi_{C 3}\right)$ & $\left(\Pi_{G 5}, \Pi_{E 5}, \Pi_{C 5}\right)$ & $\left(\Pi_{G 7}, \Pi_{E 7}, \Pi_{C 7}\right)$ \\
$\begin{array}{c}\text { Government } \\
\text { choose RS } \\
(x=0)\end{array}$ & $\left(\Pi_{G 2}, \Pi_{E 2}, \Pi_{C 2}\right)$ & $\left(\Pi_{G 4}, \Pi_{E 4}, \Pi_{C 4}\right)$ & $\left(\Pi_{G 6}, \Pi_{E 6}, \Pi_{C 6}\right)$ & $\left(\Pi_{G 8}, \Pi_{E 8}, \Pi_{C 8}\right)$ \\
\hline
\end{tabular}




\subsection{Construction of the Replicator Dynamics Equations}

According to the payoff matrix, the expected payoffs of the governments that choose to implement price subsidy policies $\left(U_{X 1}\right)$ and those that choose to implement $R \& D$ subsidy policies $\left(U_{X 2}\right)$ as well as the average payoffs of all possible strategies of the governments $\left(U_{X}\right)$ are as follows:

$$
\begin{aligned}
& U_{X 1}=y z\left(\alpha P_{1} Q_{1}+R_{3}-C_{1}-S_{1} Q_{1}\right)+y(1-z)\left(E Q_{2}+k P_{3} Q_{2}-C_{3}\right)+z(1-y)\left(\alpha P_{2} Q_{1}+R_{3}-C_{1}-(1-\delta) S_{1} Q_{1}\right) \\
& +(1-y)(1-z)\left(k P_{3} Q_{2}+E Q_{2}-C_{3}\right) \\
& =y z \alpha P_{1} Q_{1}+z(1-y) Q_{1}\left(\alpha P_{2}+\delta S_{1}\right)+z\left(R_{3}-C_{1}-S_{1} Q_{1}\right)+(1-z)\left(E Q_{2}+k P_{3} Q_{2}-C_{3}\right) \\
& U_{X 2}=y z\left(\alpha P_{1} Q_{1}+R_{3}-C_{2}-S_{2}\right)+y(1-z)\left(k P_{3} Q_{2}+E Q_{2}-C_{3}-C_{2}-S_{2}\right)+z(1-y)\left(\alpha P_{2} Q_{1}+R_{3}-C_{2}\right) \\
& +(1-y)(1-z)\left(k P_{3} Q_{2}+E Q_{2}-C_{3}-C_{2}\right) \\
& =z\left(R_{3}-C_{2}\right)-y S_{2}+z \alpha Q_{1}\left[y P_{1}+(1-y) P_{2}\right]+(1-z)\left(k P_{3} Q_{2}+E Q_{2}-C_{3}-C_{2}\right) \\
& U_{X}=x U_{X 1}+(1-x) U_{X 2}
\end{aligned}
$$

Therefore, the replicator dynamics equations for the governments that choose to implement price subsidy policies are

$$
F(x)=\frac{d x}{d t}=x\left(U_{X_{1}}-U_{X}\right)=x(1-x)\left(C_{2}+y S_{2}-z C_{1}-z S_{1} Q_{1}+z(1-y) \delta S_{1} Q_{1}\right)
$$

Similarly, the expected payoffs of the enterprises that choose high R\&D investment $\left(U_{Y 1}\right)$ and those that choose low R\&D investment $\left(U_{Y_{2}}\right)$ as well as the average payoffs for all possible strategies of the enterprises $\left(U_{Y}\right)$ are as follows:

$$
\begin{gathered}
\begin{array}{l}
U_{Y 1}=x z\left(P_{1}-M_{1}\right) Q_{1}-x M_{1} Q_{1}(1-z)+(1-x) z\left(\left(P_{1}-M_{1}\right) Q_{1}+S_{2}\right)+(1-x)(1-z)\left(S_{2}-M_{1} Q_{1}\right) \\
=z P_{1} Q_{1}-M_{1} Q_{1}+(1-x) S_{2}
\end{array} \\
\begin{array}{l}
U_{Y 2}=x z\left(P_{2}-M_{2}-\delta S_{1}\right) Q_{1}-x(1-z) M_{2} Q_{1}+(1-x) z\left(P_{2}-M_{2}\right) Q_{1}-(1-x)(1-z) M_{2} Q_{1} \\
=z P_{2} Q_{1}-M_{2} Q_{1}-x z \delta S_{1} Q_{1}
\end{array} \\
\qquad U_{Y}=y U_{Y 1}+(1-y) U_{Y 2}
\end{gathered}
$$

Thus, the replicator dynamics equations for the enterprises that choose high R\&D investment is

$$
F(y)=\frac{d y}{d t}=y\left(U_{Y 1}-U_{Y}\right)=y(1-y)\left(x z \delta S_{1} Q_{1}+(1-x) S_{2}+z\left(P_{1}-P_{2}\right) Q_{1}+\left(M_{2}-M_{1}\right) Q_{1}\right)
$$

In addition, the expected payoffs of consumers who choose to purchase NEVs $\left(U_{Z 1}\right)$ and those who choose to purchase FVs $\left(U_{Z 2}\right)$ as well as the average payoffs of all possible strategies of the consumers $\left(U_{Z}\right)$ are as follows:

$$
\begin{aligned}
& U_{\mathrm{Z} 1=}=x y\left(-P_{1}+S_{1}+F_{1}\right) Q_{1}+x(1-y)\left(-P_{2}+F_{2}+S_{1}\right) Q_{1}+(1-x) y\left(-P_{1}+F_{1}\right) Q_{1}+(1-x)(1-y)\left(-P_{2}+F_{2}\right) Q_{1} \\
& =y\left(F_{1}-P_{1}\right) Q_{1}+(1-y)\left(F_{2}-P_{2}\right) Q_{1}+x S_{1} Q_{1}
\end{aligned}
$$

The replicator dynamics equations of the consumers who choose to purchase NEVs is as follows:

$$
\begin{aligned}
F(z)=\frac{d z}{d t} & =z\left(U_{Z 1}-U_{Z}\right) \\
& =z(1-z)\left[x S_{1} Q_{1}+y\left(F_{1}-P_{1}\right) Q_{1}+(1-y)\left(F_{2}-P_{2}\right) Q_{1}-(1-y)\left(F_{3}-P_{3}-E-P_{4}\right) Q_{2}\right]
\end{aligned}
$$

We set replicator dynamics in Equations (1)-(3) to zero. There are eight stable points of the three-party system, namely, $(0,0,0),(0,0,1),(0,1,0),(0,1,1),(1,0,0),(1,0,1),(1,1,0)$ and $(1,1,1)$, 
and they represent eight pure strategies. By identifying the determinant (det) and trace (tr) sign of Jacobian matrix $(J)$, we can analyse the local stability of the stable points [30]. By taking the partial derivatives of $F(x), F(y)$ and $F(z)$ with respect to $x, y$, and $z$, we can obtain Jacobian matrix $(J)$, and the elements in Jacobian matrix $(J)$ correspond to Equations (4)-(12). The determinant and trace values of the Jacobian matrix are shown in Tables 3 and 4.

$$
\begin{gathered}
J=\left[\begin{array}{lll}
a_{1} & a_{2} & a_{3} \\
b_{1} & b_{2} & b_{3} \\
c_{1} & c_{2} & c_{3}
\end{array}\right] \\
a_{1}=\partial F(x) / \partial x=(1-2 x)\left(C_{2}+y S_{2}-z C_{1}-z S_{1} Q_{1}+z(1-y) \delta S_{1} Q_{1}\right) \\
a_{2}=\partial F(x) / \partial y=x(1-x)\left(S_{2}-z \delta S_{1} Q_{1}\right) \\
a_{3}=\partial F(x) / \partial z=x(1-x)\left(-C_{1}-S_{1} Q_{1}+(1-y) \delta S_{1} Q_{1}\right) \\
b_{1}=\partial F(y) / \partial x=y(1-y)\left(z \delta S_{1} Q_{1}-S_{2}\right) \\
b_{2}=\partial F(y) / \partial y=(1-2 y)\left(x z \delta S_{1} Q_{1}+(1-x) S_{2}+z\left(P_{1}-P_{2}\right) Q_{1}+\left(M_{2}-M_{1}\right) Q_{1}\right) \\
b_{3}=\partial F(y) / \partial z=y(1-y)\left(x \delta S_{1} Q_{1}+\left(P_{1}-P_{2}\right) Q_{1}\right) \\
c_{1}=\partial F(z) / \partial x=z(1-z) S_{1} Q_{1} \\
c_{3}=\partial F(z) / \partial z=(1-2 z)\left(\left(x S_{1}+y\left(F_{1}-P_{1}\right)+(1-y)\left(F_{2}-P_{2}\right)\right) Q_{1}-(1-y)\left(F_{3}-P_{3}-E-P_{4}\right) Q_{2}\right)
\end{gathered}
$$

Table 3. Determinant values of the Jacobian matrix.

\begin{tabular}{cc}
\hline Point & $\operatorname{det}(J)$ \\
\hline$(0,0,0)$ & {$\left[\left(M_{2}-M_{1}\right) Q_{1}+S_{2}\right]\left[\left(F_{2}-P_{2}\right) Q_{1}-\left(F_{3}-P_{3}-E-P_{4}\right) Q_{2}\right] C_{2}$} \\
$(0,0,1)$ & {$\left[C_{2}-C_{1}+(\delta-1) S_{1} Q_{1}\right]\left[S_{2}+\left(P_{1}-P_{2}+M_{2}-M_{1}\right) Q_{1}\right]\left[\left(F_{3}-P_{3}-E-P_{4}\right) Q_{2}-\left(F_{2}-P_{2}\right) Q_{1}\right]$} \\
$(0,1,0)$ & $\left(C_{2}+S_{2}\right)\left[\left(M_{1}-M_{2}\right) Q_{1}-S_{2}\right]\left[\left(F_{1}-P_{1}\right) Q_{1}\right]$ \\
$(0,1,1)$ & $\left(C_{2}+S_{2}-C_{1}-S_{1} Q_{1}\right)\left[\left(P_{2}-P_{1}+M_{1}-M_{2}\right) Q_{1}-S_{2}\right]\left[\left(P_{1}-F_{1}\right) Q_{1}\right]$ \\
$(1,0,0)$ & $\left(-C_{2}\right)\left[\left(M_{2}-M_{1}\right) Q_{1}\right]\left[S_{1} Q_{1}+\left(F_{2}-P_{2}\right) Q_{1}-\left(F_{3}-P_{3}-E-P_{4}\right) Q_{2}\right]$ \\
$(1,0,1)$ & {$\left[C_{1}-C_{2}+(1-\delta) S_{1} Q_{1}\right]\left[-S_{1} Q_{1}-\left(F_{2}-P_{2}\right) Q_{1}+\left(F_{3}-P_{3}-E-P_{4}\right) Q_{2}\right]\left(\delta S_{1}+P_{1}-P_{2}+M_{2}-M_{1}\right) Q_{1}$} \\
$(1,1,0)$ & $\left(-C_{1}-S_{2}\right)\left(M_{1}-M_{2}\right)\left(S_{1}+F_{1}-P_{1}\right) Q_{1}^{2}$ \\
$(1,1,1)$ & $\left(C_{1}-C_{2}-S_{2}+S_{1} Q_{1}\right)\left(-\delta S_{1}+P_{2}-P_{1}+M_{1}-M_{2}\right)\left(-S_{1}+P_{1}-F_{1}\right) Q_{1}^{2}$ \\
\hline
\end{tabular}

Table 4. Trace values of the Jacobian matrix.

\begin{tabular}{cc}
\hline Point & $\operatorname{tr}(J)$ \\
\hline$(0,0,0)$ & $C_{2}+S_{2}+\left(F_{2}-P_{2}+M_{2}-M_{1}\right) Q_{1}-\left(F_{3}-P_{3}-E-P_{4}\right) Q_{2}$ \\
$(0,0,1)$ & $C_{2}+\left(M_{1}-M_{2}+F_{1}-P_{1}\right) Q_{1}$ \\
$(0,1,0)$ & $C_{2}-C_{1}-S_{1} Q_{1}+\left(P_{2}+M_{1}-M_{2}-F_{1}\right) Q_{1}$ \\
$(0,1,1)$ & $C_{2}-C_{1}+S_{2}+\left(\delta S_{1}-S_{1}+Q_{2}\right.$ \\
$(1,0,0)$ & $C_{2}+\left(M_{2}-M_{1}+S_{1}+F_{2}-P_{2}\right) Q_{1}-\left(F_{3}-P_{3}-E-P_{4}\right) Q_{2}$ \\
$(1,0,1)$ & $C_{1}-C_{2}+\left(P_{1}-F_{2}+M_{2}-M_{1}\right) Q_{1}+\left(F_{3}-P_{3}-E-P_{4}\right) Q_{2}$ \\
$(1,1,0)$ & $-C_{2}-S_{2}+\left(M_{1}-M_{2}+S_{1}+F_{1}-P_{1}\right) Q_{1}$ \\
$(1,1,1)$ & $C_{1}-C_{2}-S_{2}-\delta S_{1} Q_{1}+\left(P_{2}-F_{1}+M_{1}-M_{2}\right) Q_{1}$ \\
\hline
\end{tabular}

The results shown in Tables 3 and 4 indicate that, due to the complexity of the model, the existing conditions cannot directly determine the stability of the above equilibrium points, and the results of a direct numerical analysis are tedious and not intuitive. Therefore, we use SD to carry out the remainder of the research. SD focuses on the dynamic changes in the system and the influence of the factors; therefore, SD provides an effective alternative method of studying the complex dynamic evolution process of evolutionary games under incomplete information [31]. Considering the current NEV market, we use SD simulation to establish the evolution game model of the NEV market system and analyse the impacts of the initial conditions and changes in different factors on the evolution process. 


\section{Simulation Analysis of a Tripartite Evolutionary Game Based on SD}

In this section, we combine evolutionary game theory with SD to simulate the evolutionary game behaviour of the government, enterprises and consumers.

Based on the analysis results of the evolutionary game, we use Vensim PLE to establish the SD simulation model of the governments, enterprises and consumers, as shown in Figure 1. $x, y$ and $z$ represent the stock, time integral of the change rate of government subsidy policy and the R\&D level of the enterprises and consumers' purchase choices, respectively; $d x / d t, d y / d t$ and $d z / d t$ represent the change rates of three types of stock; and $U_{X 1}, U_{X 2}, U_{Y 1}, U_{Y 2}, U_{Z 1}$ and $U_{Z 2}$ represent six intermediate variables. The remaining parameters represent variables outside the system boundary and thus are exogenous variables.

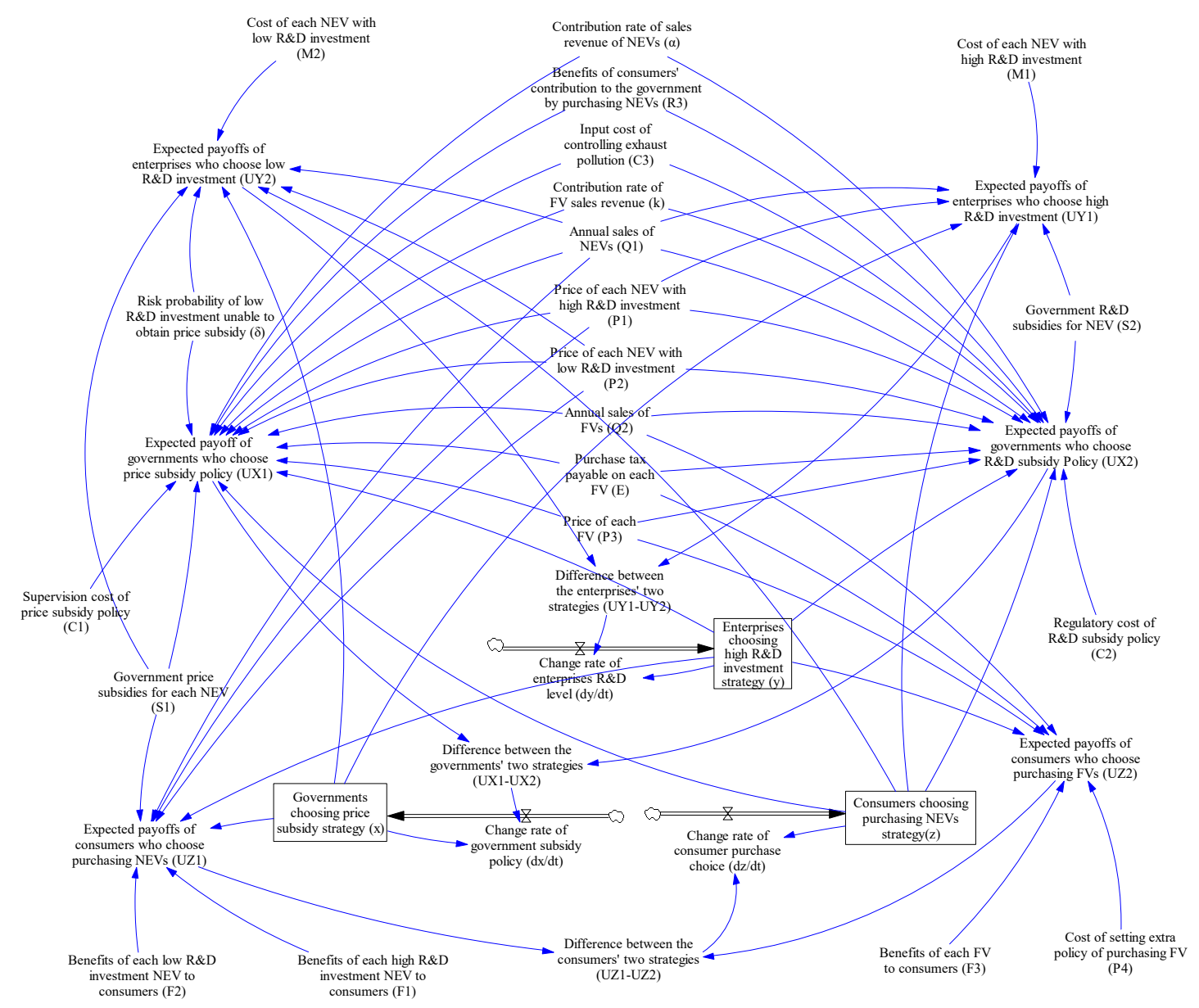

Figure 1. SD simulation model of governments, enterprises and consumers.

We can write the relations and equations of the variables in the model using Equations (1)-(3), which clearly describe the relations among the variables. According to the principles for constructing SD simulation models, to more accurately describe the game among the government, enterprises and consumers, the selection of all simulation values in this paper are based on publicly available information on the official website for the government's subsidy policy, the financial statements of automobile companies and information obtained from the China Association of Automobile Manufacturers and by networking with car owners. Based on these findings, a SD model is developed to simulate the evolutionary game process of the current NEV market so that scientific suggestions can be made to optimise subsidy policies and to help enterprises understand the future direction of development. In addition, the monthly sales volume of each type of vehicle has been characterised by large fluctuations and irregularities in recent years [1]. Therefore, we use the monthly average sales 
volume derived from the annual sales volume to substitute into the model, making the model more appropriate. We set INITIAL TIME $=0$, FINAL TIME $=100$, TIME STEP $=1$, and UNITS FOR TIME: Month. To ensure the consistency of the numerical units used in the calculation, we standardise the units, which leads to a large difference in the order of magnitude of some parameters. The parameters used in the SD model are shown in Table 5.

Table 5. Input parameters of the simulation.

\begin{tabular}{ccccc}
\hline Variables & Type & Value & Multiplier & Description \\
\hline$Q_{1}$ & Constant & 5.75 & Thousand & Vehicles \\
$Q_{2}$ & Constant & 44.6 & Thousand & Vehicles \\
$F_{1}$ & Constant & 0.15 & Million & RMB \\
$F_{2}$ & Constant & 0.11 & Million & RMB \\
$R_{3}$ & Constant & 0.006 & Billion & RMB \\
$k$ & Constant & 0.03 & - & Dmnl \\
$\alpha$ & Constant & 1 & - & Dmnl \\
$M_{1}$ & Constant & 0.1 & Million & RMB \\
$M_{2}$ & Constant & 0.07 & Million & RMB \\
$S_{2}$ & Constant & 0.14 & Billion & RMB \\
$C_{3}$ & Constant & 0.5 & Billion & RMB \\
$P_{3}$ & Constant & 0.067 & Million & RMB \\
$P_{1}$ & Constant & 0.16 & Million & RMB \\
$P_{2}$ & Constant & 0.13 & Million & RMB \\
$E$ & Constant & 0.0067 & Million & RMB \\
$C_{2}$ & Constant & 0.004 & Billion & RMB \\
$C_{1}$ & Constant & 0.0035 & Billion & RMB \\
$F_{3}$ & Auxiliary & $0.09+$ RAMP & Million & RMB \\
& & $(-0.0005,0,50)$ & & \\
$P_{4}$ & Auxiliary & $0.01+$ RAMP & Million & RMB \\
$S_{1}$ & & $(0.0001,0,50)$ & & \\
& Auxiliary & $0.02+$ RAMP & Million & RMB \\
$\delta$ & & $(-0.0002,10,50)$ & & \\
& Auxiliary & $0.5+$ RAMP & & Dmnl \\
\hline
\end{tabular}

\subsection{Effect of the Initial Market Proportions of the Three Parties on the Game's Equilibrium}

In this section, we discuss the evolution trend of the governments, enterprises and consumers when their initial proportions differ. First, when the initial strategies of the governments, enterprises and consumers are all pure strategies, there are eight possible situations, namely $(0,0,0),(0,1,0)$, $(0,0,1),(0,1,1),(1,0,0),(1,1,0),(1,0,1)$ and $(1,1,1)$. When the parties choose these strategies, the parties do not change during the evolution process and the system is in equilibrium.

When any party chooses a mixed strategy, that is, when the strategies chosen by all participants of the same type in the market are not completely consistent, the system will gradually change from an unstable state to a stable state, which is consistent with reality. We assume that, when half of the governments choose the price subsidy policy, half of the enterprises choose the high R\&D investment, and half of the consumer group choose to purchase NEVs. The evolution process of the three parties is shown in Figure 2.

We find that, if the initial market proportion of the three stakeholders is $(0.5,0.5,0.5)$, all groups will choose $(1,1,1)$ as their final strategy. The governments choose to continue to implement their price subsidy policies, the enterprises choose a high R\&D investment level to develop NEVs, and the consumers choose to purchase NEVs; this is the best strategy for all groups. From the results in Figure 2, we can obtain Insights 4.1-4.3. 


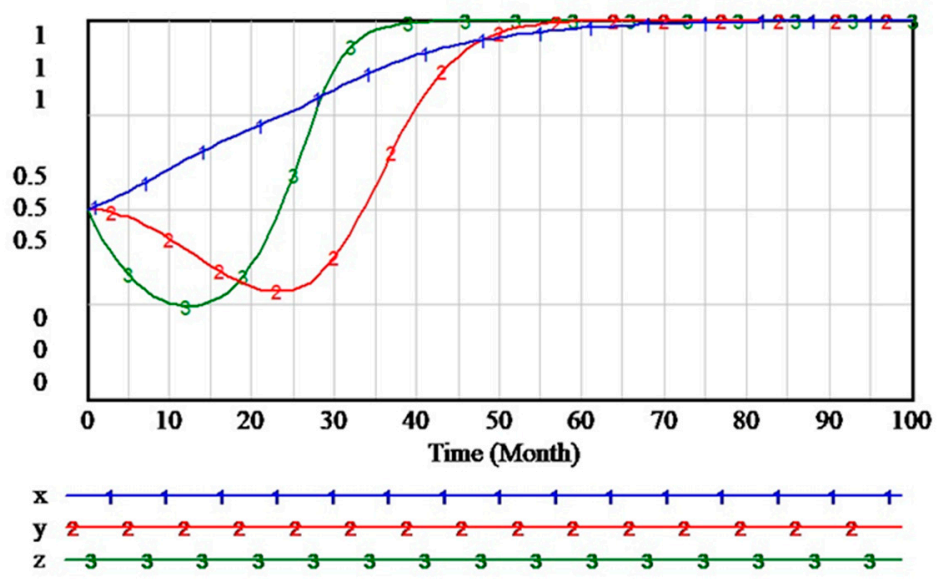

Figure 2. Evolution strategies of the governments, enterprises and consumers.

Insight 4.1. For governments, the price subsidy policy is still the best subsidy policy in the NEV market [7]. Over time, the number of governments choosing price subsidies in the market steadily increases. In 49.8 months, 95\% of the governments choose the price subsidies. Then, the system gradually reaches the ESS.

Insight 4.2. In the future, producing high-quality NEVs is the first choice of EV enterprises. In the initial market, the proportion of enterprises that choose low RED investment gradually increases. In 21.9 months, the proportion of enterprises that choose high RED investment reaches its lowest value, of $30 \%$. Then, the number of enterprises that choose high RED investment increases gradually. After 47.7 months, almost the entire enterprise group chooses the strategy of high RED investment until the system reaches the ESS.

Insight 4.3. For consumers, choosing to purchase NEVs is the best strategy, which is in line with the governments' ultimate goal of implementing financial subsidy policies. In the early stage, the trend of consumers purchasing FVs gradually increased. At 11.9 months, the number of consumers who choose to purchase FVs reached its maximum at $74 \%$ of the total consumers. Then, the number of consumers who purchase NEVS steadily increased. In 33.9 months, almost the entire consumer group chooses NEVs, and the game will eventually stabilise at $x=1$.

To explore the influence of different initial proportions of the governments, enterprises and consumers on the strategies they choose, we ran a simulation in which the initial proportions are $0.25,0.5$ and 0.75 , respectively. Let $\mathrm{x}^{\prime}, \mathrm{y}^{\prime}$, and $\mathrm{z}^{\prime}$ represent the initial proportions of the governments, enterprises and consumers. The simulation results are shown in Figures 3-5. From these results, Insights 4.4-4.6 can be obtained.

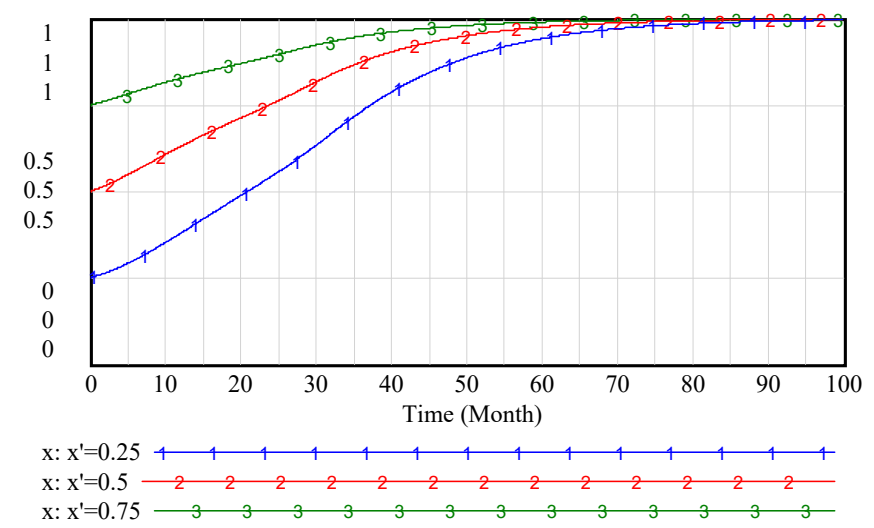

Figure 3. Evolution of the governments' strategy. 

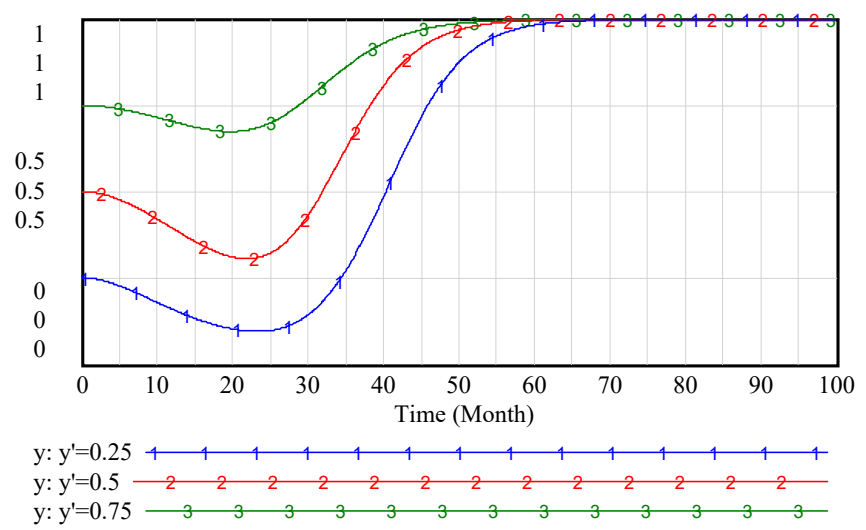

Figure 4. Evolution of the enterprises' strategy.
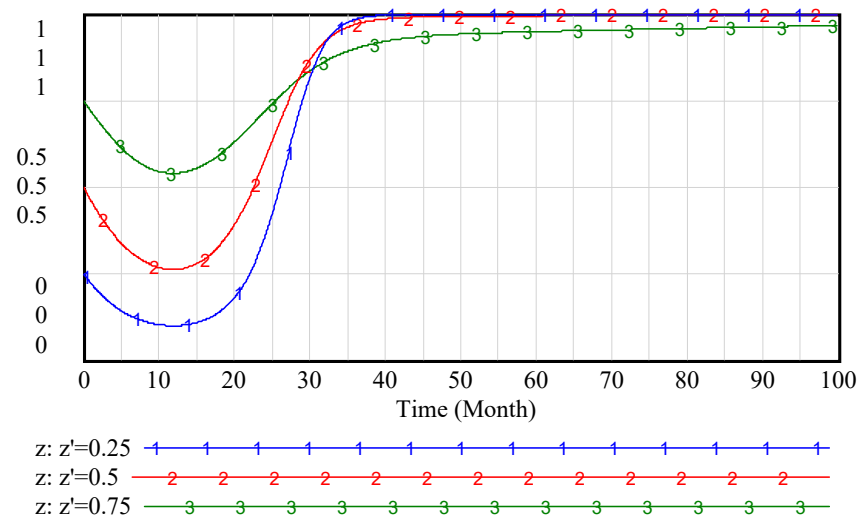

Figure 5. Evolution of the consumers' strategy.

Insight 4.4. As shown in Figure 3, when the initial proportion of governments choosing price subsidies in the market varies, all the governments tend to adopt price subsidy policies after several months, which suggests that the governments' policy of gradually reducing price subsidies may not be an effective long-term strategy. Under the current market conditions, if the price subsidy policies continue to be adopted, they can effectively stimulate consumers to purchase NEVs.

Insight 4.5. As shown in Figure 4, when the initial proportion of enterprises that choose high RED investment in the market varies, their evolution trend tends to be consistent. In three cases, the number of enterprises that initially choose high RED investment decreases gradually and reaches the lowest value between 19.7 and 23.3 months, and then the number of enterprises that choose high RED investment gradually increases. As the initial value becomes larger, it takes less time to reach the minimum value, and it takes less time to reach the final ESS. This finding shows that, regardless of the initial proportion, choosing high RED investment is the right strategy for adapting to the long-term development trend of the market.

Insight 4.6. As shown in Figure 5, when the initial proportion of consumers who choose to purchase NEVs in the market varies, the proportion first decreases and then increases. Compared with Insight 4.5, when the initial value is increased, it takes a longer time to reach the ESS; when the initial value is decreased, it takes a shorter time to reach the ESS.

\subsection{Analysis of the Influence of Other Factors on the Strategy Selections of Game Groups}

In this section, we choose three factors and study the influence of these factors on the evolution of the strategy choices of the three groups. The three factors are government R\&D subsidies for enterprises, enterprises with a high R\&D investment cost and consumers' extra cost for purchasing 
FVs. From the previous section, we know that the initial proportion of the three groups changes only the time and speed of evolution and does not affect the final result of the evolution. Therefore, we use the initial market proportion $(0.5,0.5,0.5)$ for the following simulation.

\subsubsection{Effect of Government R\&D Subsidies on Game Equilibrium}

We set the government $R \& D$ subsidies for enterprises to $0.1,0.14,0.18$ and 0.22 . The results shown in Figures 6-8 lead us to develop Insights 4.7-4.9, respectively.

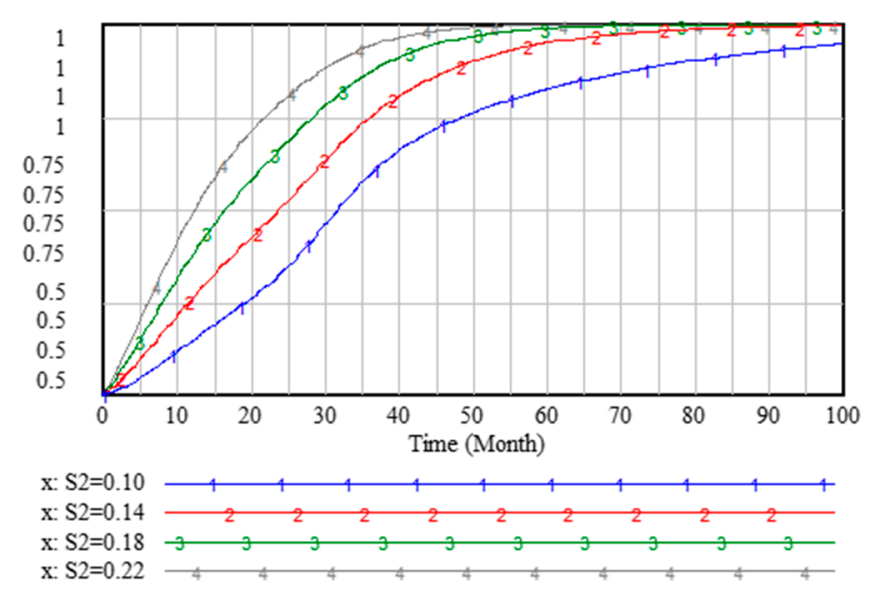

Figure 6. The effect of R\&D subsidies on governments' strategy.
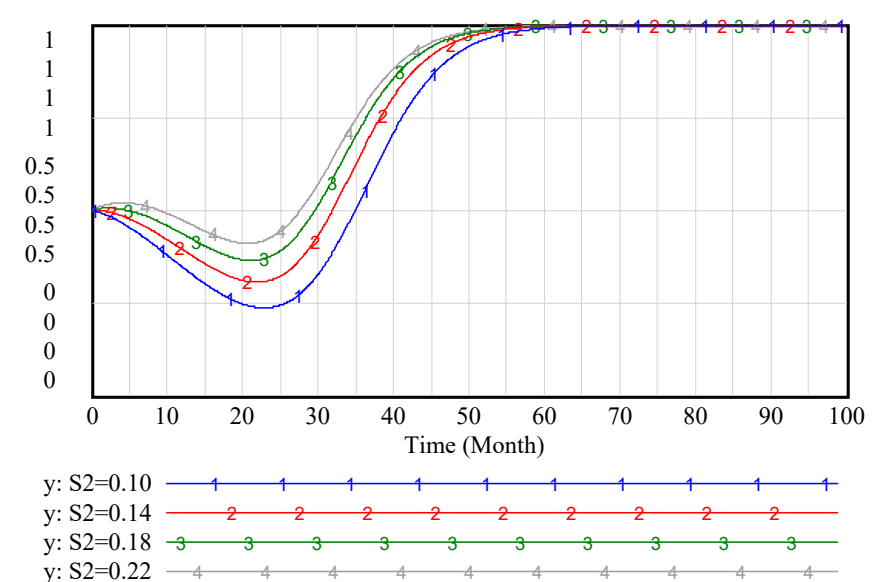

Figure 7. The effect of R\&D subsidies on enterprises' strategy.

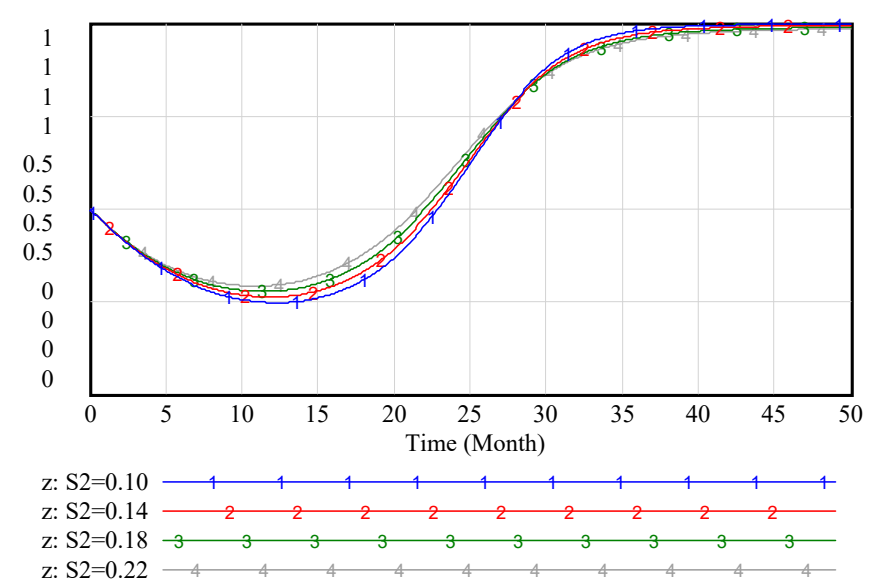

Figure 8. The effect of R\&D subsidies on consumers' strategy. 
Insight 4.7. The governments are incentivised to provide RED subsidies. The higher the governments' RED subsidy parameter is, the faster the governments will choose the price subsidy policy.

Insight 4.8. The governments' RED subsidies incentivise enterprises to choose high RED investment, although the trend of evolution will first decrease and then increase until it reaches the ESS. As the cost of NEVs is still higher than that of FVs and the price of NEVs is still at a high level in the market, the governments should choose to increase the RED subsidies for enterprises over a period of time. This insight is consistent with the findings of Zhang et al. [8].

Insight 4.9. The governments' RED subsidy values have little influence on the consumers' choices, which shows that increasing the governments' RED subsidy values has no obvious incentive effect on the consumers' choice to purchase NEVs. Over time, the possibility that consumers will choose to purchase NEVs first decreases and then increases until it reaches the ESS. At 40.9 months, almost all consumers will choose to purchase NEVs.

\subsubsection{Effect of Enterprises' High R\&D Investment Cost on Game Equilibrium}

We set the enterprises' high R\&D investment cost parameter at $0.08,0.1,0.12$ and 0.14 . From the results shown in Figures 9-11, we can obtain Insights 4.10-4.12, respectively.

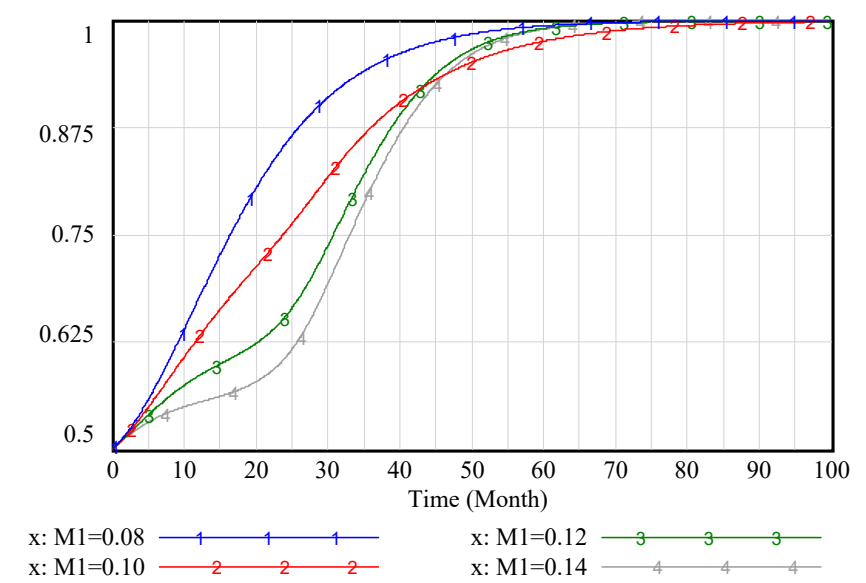

Figure 9. Effect of a high R\&D cost on governments' strategies.

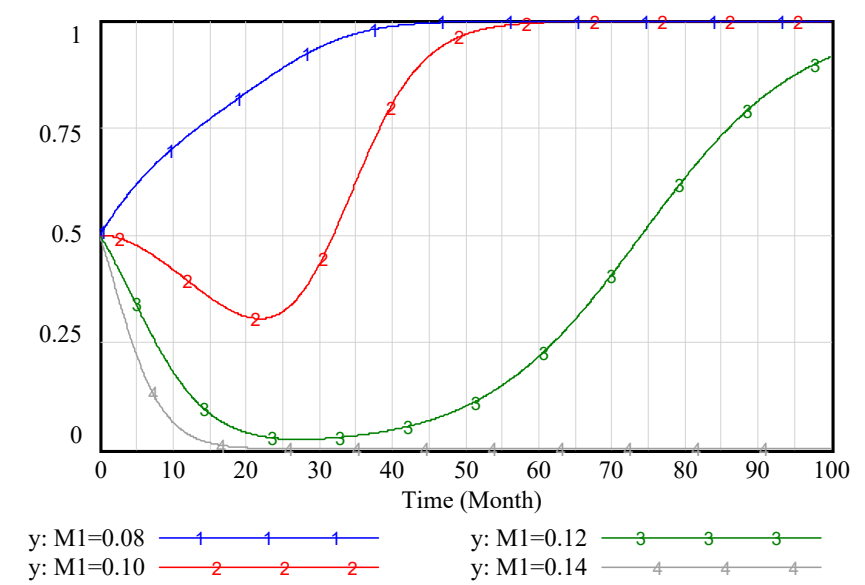

Figure 10. Effect of a high R\&D cost on enterprises' strategies. 


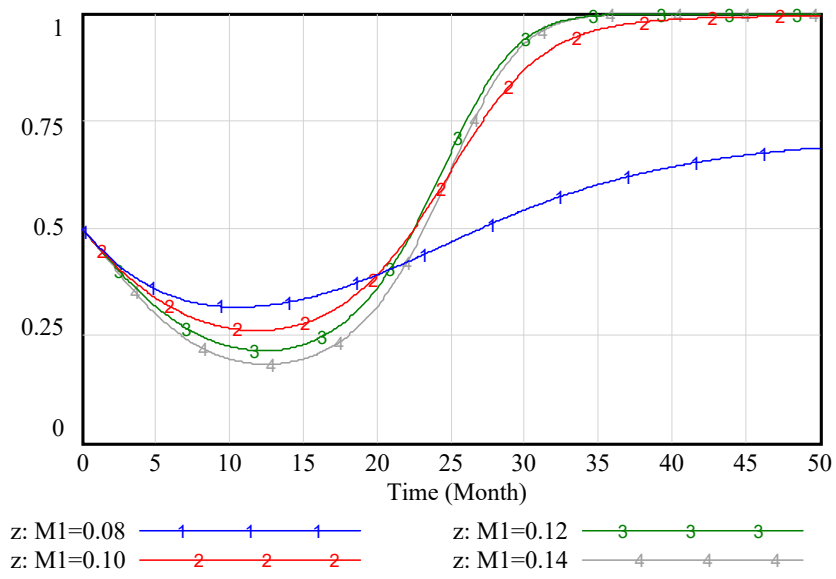

Figure 11. Effect of a high R\&D cost on consumers' strategies.

Insight 4.10. In the first 43.2 months, the higher is the cost of the RED investment, the greater is the probability that the governments will choose RED subsidies. However, over the long term, the governments will gradually begin choosing price subsidies. The change in the high RED investment cost does not affect the governments' optimal strategy.

Insight 4.11. When the high RED investment cost is set at a low value, the enterprises will choose a high RED investment strategy. If the cost increases to a level near the NEV sales price, then the enterprises will reduce their RED and then choose low RED investment to ensure the companies can maintain a certain profit.

Insight 4.12. Excessive RED cost savings will have a negative impact on consumers' experiences of using NEVs. When high RED investments are set at a high value, all consumers choose to purchase NEVs within 34.8 months. However, only $60 \%$ of the consumers choose to purchase NEVs when high RED investment is set at a low level. Excessive RED cost savings reduce the possibility that consumers will purchase NEVs, and the time it takes to reach the goal of the universal popularisation of NEVs will be greatly increased. These results show that it is important for enterprises to increase their RED investment, and this insight is consistent with the findings of Meng and Jin [9]. When the RED investment cost is in the normal range, it will not have much of an impact on the consumer market.

\subsubsection{Effect of Consumers' Extra Cost for Purchasing FVs on Game Equilibrium}

Based on the results shown in Figures 12-14, we can obtain Insights 4.13-4.15, respectively.

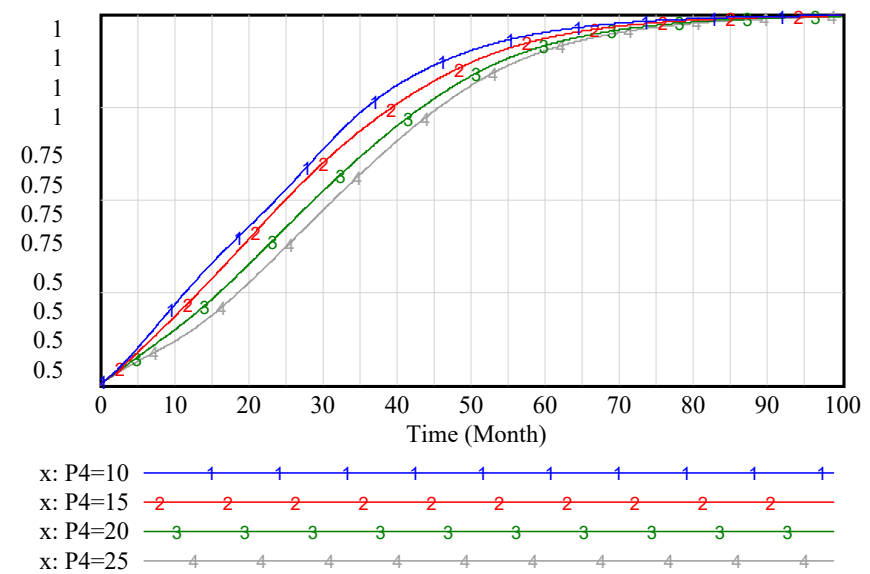

Figure 12. Effect of the extra cost of purchasing FV on governments' strategies. 

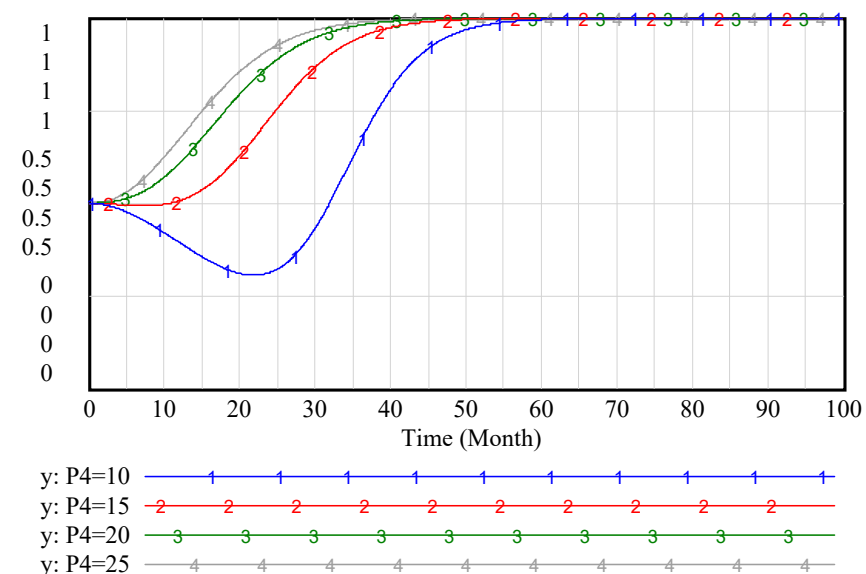

Figure 13. Effect of the extra cost of purchasing FV on enterprises' strategies.

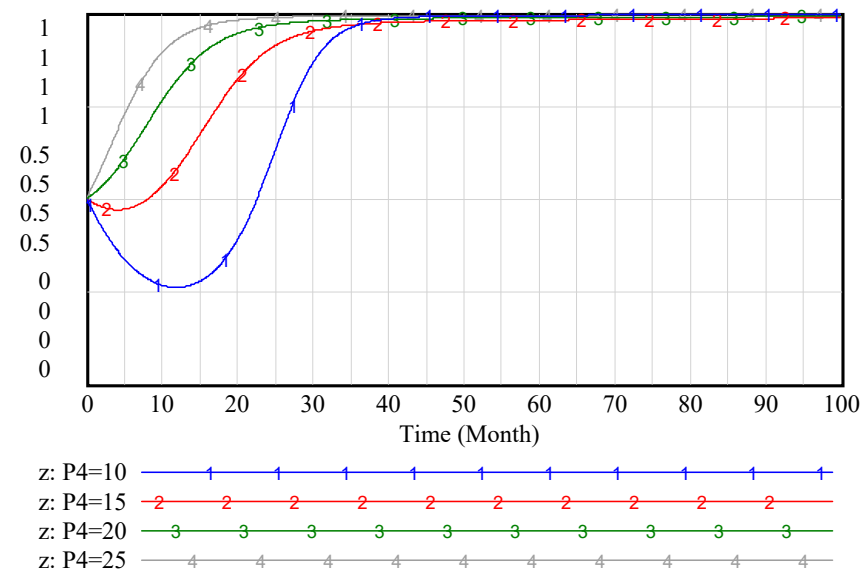

Figure 14. Effect of the extra cost of purchasing FV on consumers' strategies.

Insight 4.13. The impact of consumers' extra cost for purchasing FVs on the governments' strategy choices is not significant, and the change will not affect the general trend of the governments' strategies. When consumers' extra cost for purchasing FVs is in a low range, to effectively encourage consumers to purchase NEVs, the governments will increase the intensity of the price subsidies offered to consumers, which is also the best strategy for the government.

Insight 4.14. Consumers' extra cost for purchasing FVs has a great influence on the strategy decisions of the enterprises. For example, if consumers' extra cost for purchasing FVs increases by 2.5 times (from 10 thousand to 25 thousand), then, in the 25th month, the proportion of enterprises that choose high RED investment increases by 2.88 times (from $32.1 \%$ to $92.7 \%$ ). When consumers' extra cost for purchasing FVs stays in a low range, then the possibility that enterprises will choose high RED investment initially decreases and then increases. When the consumers' extra cost for purchasing FVs increases, the proportion of high RED investment enterprises will directly increase until the ESS is reached.

Insight 4.15. The increase in the consumers' extra cost for purchasing FVs has an obvious incentive effect on consumers and induces them to purchase NEVs. For example, if consumers' extra cost for purchasing FVs increases by 2.5 times (from 10 thousand to 25 thousand), then, in the 15th month, the proportion of consumers choosing to purchase NEVs increases by 3.47 times (from $27.7 \%$ to $96.2 \%$ ). However, the temporal trend change of consumers is ahead of that of enterprises, and the two groups change with the same trend. When the proportion of consumers choosing to purchase NEVs increases, the proportion of enterprises choosing high RED investment will also increase after a period of time. This finding shows that the current supply chain of NEVs is a pull 
supply chain; that is, customers are the leader of the supply chain, and the enterprises' choice of production strategy will change according to the change in consumer market demand.

\section{Conclusions and Directions for Further Research}

\subsection{Implications for Theory and Practice}

In this paper, we analyse the subsidy policy for the Chinese NEV market using the evolutionary game and SD methods. We made our conclusions from theoretical and practical perspectives.

From a theoretical perspective, we obtain conclusions in two cases: pure strategy and mixed strategy. When all three players choose a pure strategy, the NEV market will become stable when other conditions do not change; that is, the governments, enterprises and consumers will not change their choice of strategy. When all three players choose a mixed strategy, we can summarise it by the transverse direction and the longitudinal direction. In the transverse direction, different initial market proportions will not change the final strategy choices of the three parties but will affect the evolution's time and speed. The consumer market has the fastest reaction, followed by the enterprises and finally the governments. In the end, governments will choose to implement price subsidy policies, NEV enterprises will choose high R\&D investment and consumers will choose to purchase NEVs. In the longitudinal direction, for governments and enterprises, the higher are the initial market proportions that, respectively, choose price subsidies and high $R \& D$ investment, the shorter is the time it takes to reach evolutionary stability. For consumers, the higher is the initial proportion that choose to purchase NEVs, the shorter is the time it takes to reach the final evolutionary stability, which shows that a market with a low initial proportion of NEVs has greater potential.

From a practical perspective, the exogenous variables, such as government R\&D subsidies, enterprise R\&D investment and consumers' extra cost for purchasing FVs, will affect the strategic behaviour of the governments, enterprises and consumers. In particular, when R\&D investment of enterprises is set at a low level, the time for consumers to reach evolutionary stability will greatly increase; when R\&D investment of enterprises is set at a high level, the government's evolutionary stability strategy will change from choosing high R\&D investment to low R\&D investment. Thus, we provide three suggestions for guiding consumers to purchase NEVs. For governments, it is unwise to hastily cancel the price subsidies offered to consumers. Currently, the price of NEVs is much higher than that of FVs. Governments should offer a reasonable level of subsidies according to the actual development of the NEV market and dynamically adjust the rate of the decrease in the subsidies. For enterprises, a moderate increase in R\&D investment can increase the percentage of the future market share of consumers and guide consumers to choose to purchase NEVs in a shorter period of time. In the future, NEV enterprises should pay more attention to the R\&D of NEVs and improve their core competitiveness. However, if the cost of $R \& D$ cost is so high that it is close to the selling price and the enterprise cannot guarantee the sales profit, the enterprise should choose the low R\&D investment strategy rather than the high R\&D investment. Increasing consumers' extra cost for purchasing FVs or maintaining the government's price subsidies offered to consumers can effectively motivate consumers to purchase NEVs, which shows that the current consumer market attaches great importance to the purchase price of vehicles and most consumers have great interest in these prices.

\subsection{Limitations and Directions for Further Research}

This article has some limitations. On the one hand, our work is based on the current subsidy policy and conducts theoretical research on the entire NEV market. However, the market positioning of each NEV enterprise is different. In the future, we can combine the data on specific NEV enterprises to conduct empirical research, which would be more practical for specific NEV enterprises [2,9]. On the other hand, China's NEV market is still a policy-driven market. This paper mainly analyses the mechanism of the interactions among the various game groups based on the imperfect subsidy 
policy. However, there are other issues impeding NEV development, such as local protectionism and mismatched charging infrastructure [8,32].

This study could be extended for further research in these directions. First, NEV industry is still complex and fluctuant in China [1]; with huge expected growth rates of vehicles in the following years, it would be very interesting to consider the sales prediction of the vehicle market and analyse the behaviours of the NEV market stakeholders. Second, from the vehicle market, since the change of vehicle price is affected by many factors, another meaningful research direction is to consider the price change into the model.

Author Contributions: Conceptualisation, H.S. and Y.W.; Investigation, Y.W. and H.L.; Methodology, H.S. and H.L.; Supervision, H.S.; Writing - original draft, Y.W.; and Writing-review and editing, H.S. and Y.W. All authors have read and agreed to the published version of the manuscript.

Funding: This study was supported by Beijing Social Science Foundation(17GLC046) and National Natural Science Foundation of China (71871002).

Acknowledgments: We sincerely thank the editor and three anonymous reviewers for their kind and helpful comments on this paper.

Conflicts of Interest: We declare that we have no conflicts of interest to this work.

\section{References}

1. Liu, C.; Huang, W.; Yang, C. The evolutionary dynamics of China's electric vehicle industry-Taxes vs. subsidies. Comput. Ind. Eng. 2017, 113, 103-122. [CrossRef]

2. Yu, P.; Zhang, J.; Yang, D.F.; Lin, X.; Xu, T.Y. The evolution of China's new energy vehicle industry from the perspective of a technology-market-policy framework. Sustainability 2019, 11, 1711. [CrossRef]

3. Li, Y.; Zeng, B.; Wu, T.; Hao, H. Effects of urban environmental policies on improving firm efficiency: Evidence from Chinese new energy vehicle firms. J. Clean. Prod. 2019, 215, 600-610. [CrossRef]

4. Li, T.C.; Han, D.R.; Feng, S.S.; Liang, L. Can industrial co-agglomeration between producer services and manufacturing reduce carbon intensity in China? Sustainability 2019, 11, 4024. [CrossRef]

5. Sun, H.X.; Wan, Y.; Zhang, L.L.; Zhou, Z. Evolutionary game of the green investment in a two-echelon supply chain under a government subsidy mechanism. J. Clean. Prod. 2019, 235, 1315-1326. [CrossRef]

6. Mol, A.P.J.; Carter, N.T. China's environmental governance in transition. Environ. Polit. 2006, 15, 149-170. [CrossRef]

7. Jiang, C.L.; Zhang, Y.; Bu, M.L.; Liu, W.S. The effectiveness of government subsidies on manufacturing innovation: Evidence from the new energy vehicle industry in China. Sustainability 2018, 10, 1692. [CrossRef]

8. Zhang, X.P.; Rao, R.; Xie, J.; Liang, Y.N. The current dilemma and future path of china's electric vehicles. Sustainability 2014, 6, 1567-1593. [CrossRef]

9. Meng, F.S.; Jin, X.Y. Evaluation of the development capability of the new energy vehicle industry: An empirical study from China. Sustainability 2019, 11, 2635. [CrossRef]

10. Starrs, S. American economic power hasn't declined-it globalized! summoning the data and taking globalization seriously. Int. Stud. Q. 2013, 57, 817-830. [CrossRef]

11. Driscoll, A.; Lyons, S.; Mariuzzo, F.; Tol, R.S.J. Simulating demand for electric vehicles using revealed preference data. Energy Policy 2013, 62, 686-696. [CrossRef]

12. Hirte, G.; Tscharaktschiew, S. The optimal subsidy on electric vehicles in German metropolitan areas: A spatial general equilibrium analysis. Energy Econ. 2013, 40, 515-528. [CrossRef]

13. Li, J.; Jiao, J.; Tang, Y. An evolutionary analysis on the effect of government policies on electric vehicle diffusion in complex network. Energy Policy 2019, 129, 1-12. [CrossRef]

14. Yang, Z.Y.; Tang, M.P. Welfare analysis of government subsidy programs for fuel-efficient vehicles and new energy vehicles in China. Environ. Res. Econ. 2019, 74, 911-937. [CrossRef]

15. Wu, T.; Ma, L.; Mao, Z.; Ou, X. Setting up charging electric stations within residential communities in current China: Gaming of government agencies and property management companies. Energy Policy 2015, 77, 216-226. [CrossRef]

16. Li, J.Z.; Ku, Y.Y.; Liu, C.L.; Zhou, Y.P. Dual credit policy: Promoting new energy vehicles with battery recycling in a competitive environment? J. Clean. Prod. 2020, 243, 118456. [CrossRef] 
17. Luo, C.; Leng, M.; Huang, J.; Liang, L. Supply chain analysis under a price-discount incentive scheme for electric vehicles. Eur. J. Oper. Res. 2014, 235, 329-333. [CrossRef]

18. Sun, X.; Liu, X.; Wang, Y.; Yuan, F. The effects of public subsidies on emerging industry: An agent-based model of the electric vehicle industry. Technol. Forecast. Soc. Chang. 2019, 140, 281-295. [CrossRef]

19. Yang, D.X.; Qiu, L.-S.; Yan, J.-J.; Chen, Z.-Y.; Jiang, M. The government regulation and market behavior of the new energy automotive industry. J. Clean. Prod. 2019, 210, 1281-1288. [CrossRef]

20. Zuo, W.; Li, Y.; Wang, Y. Research on the optimization of new energy vehicle industry research and development subsidy about generic technology based on the three-way decisions. J. Clean. Prod. 2019, 212, 46-55. [CrossRef]

21. Smith, J.M. Evolution and the theory of games. In Did Darwin Get It Right? Springer: Boston, MA, USA, 1988; pp. 202-215.

22. Taylor, P.D.; Jonker, L.B. Evolutionary stable strategies and same dynamics. Math. Biosci. 1978, 40, 145-156. [CrossRef]

23. Wang, S.Y.; Fan, J.; Zhao, D.T.; Wu, Y.R. The impact of government subsidies or penalties for new-energy vehicles a static and evolutionary game model analysis. J. Transp. Econ. Policy 2015, 49, 98-114.

24. Forrester, J.W. Industrial dynamics: A major breakthrough for decision makers. Harv. Bus. Rev. 1958, 36, $37-66$.

25. Trappey, A.J.C.; Trappey, C.; Hsiao, C.T.; Ou, J.J.R.; Li, S.J.; Chen, K.W.P. An evaluation model for low carbon island policy: The case of Taiwan's green transportation policy. Energy Policy 2012, 45, 510-515. [CrossRef]

26. Lee, Y.; Kim, C.; Shin, J. A hybrid electric vehicle market penetration model to identify the best policy mix: A consumer ownership cycle approach. Appl. Energy 2016, 184, 438-449. [CrossRef]

27. Zhang, X.; Liang, Y.; Liu, W. Pricing model for the charging of electric vehicles based on system dynamics in Beijing. Energy 2017, 119, 218-234. [CrossRef]

28. Lu, C.; Liu, H.-C.; Tao, J.; Rong, K.; Hsieh, Y.-C. A key stakeholder-based financial subsidy stimulation for Chinese EV industrialization: A system dynamics simulation. Technol. Forecast. Soc. Chang. 2017, 118, 1-14. [CrossRef]

29. Sun, S.; Wang, W. Analysis on the market evolution of new energy vehicle based on population competition model. Transp. Res. Part D Transp. Environ. 2018, 65, 36-50. [CrossRef]

30. Friedman, D. Evolutionary games in economics. Econometrica 1991, 59, 637-666. [CrossRef]

31. Karnopp, D.; Rosenberg, R.C.; Perelson, A. System Dynamics: A Unified Approach; John Wiley \& Sons Inc.: Hoboken, NJ, USA, 1990.

32. Yang, L.; Hao, C.X.; Tang, R.H. Location models of charging and battery swapping facilities based on electric vehicles. Syst. Eng. Theory Pract. 2019, 39, 1781-1795. [CrossRef] 